\title{
KAPASITAS JARINGAN SOSIAL DAN KEBIJAKAN REVITALISASI PELABUHAN PERIKANAN DI PULAU TERDEPAN (Pelajaran dari Revitalisasi Pangkalan Pendaratan Ikan Lugu, di Kabupaten Simeulue) Social Networking Capacity and The Policy of Revitalization of Fishing Port in The Frontier Island (A Lesson From Revitalization of Lugu Fishing Port, in Simeulue Regency)
}

\author{
*Armen Zulham \\ Pusat Penelitian Sosial Ekonomi Kelautan dan Perikanan \\ Gedung Balitbang KP I Lt. 4 \\ Jalan Pasir Putih Nomor 1 Ancol Timur, Jakarta Utara, Indonesia \\ Telp: (021) 64711583 Fax: 64700924
}

Diterima tanggal: 13 September 2016 Diterima setelah perbaikan: 15 Oktober 2016 Disetujui terbit: 8 Desember 2016

"email: keude_bing@yahoo.co.id

\begin{abstract}
ABSTRAK
Pembangunan ekonomi pulau terdepan melalui program Sentra Kelautan dan Perikanan Terpadu (SKPT) sedang giat dilakukan. Program ini merupakan kegiatan andalan Kabupaten Simeulue dalam bentuk kegiatan renovasi pabrik es, air blast freezer, docking kapal serta membangun pertokoan dan perkantoran pada Pangkalan Pendaratan Ikan (PPI) Lugu. Pembangunan infrastruktur tersebut diharapkan mendorong berkembangnya bisnis perikanan, memfungsikan (revitalisasi) PPI Lugu, dan meningkatkan kontribusi Lapangan Usaha Perikanan pada PDRB Kabupaten Simeulue. Tujuan tulisan ini adalah mempelajari jaringan sosial dan mencari strategi revitalisasi (memfungsikan) PPI Lugu Pengamatan lapangan untuk tujuan revitalisasi PPI Lugu, dilakukan melalui survei cepat pada Januari 2015 dan wawancara mendalam terhadap 30 responden nelayan dan 3 responden "toke bangku" tentang aspek sosial ekonomi dan bisnis perikanan pada April 2016. Data di analisis secara deskriptif dan berdasarkan teori ekonomi mengacu teori Henderson and Quant dan teori sosiologi ekonomi mengacu teori Damsar dan Indrayani. Hasil penelitian ini menunjukkan peran dan kapasiatas pelaku bisnis, jaringan sosial, pertukaran sosial pada bisnis perikanan di Simeulue tidak dijadikan dasar dalam menyusun kebijakan merevitalisasi PPI Lugu. Hal ini menyebabkan, sampai bulan Agustus 2016 PPI belum berfungsi. Tulisan ini merekomendasikan, operasional PPI Lugu, dilakukan dalam dua tahap: jangka pendek dengan memberi konsesi pada perusahaan/ pengusaha yang memiliki modal dan jaringan pasar yang luas untuk mengelola Cold Storage dan ABF atau Pabrik es. Jangka panjang mulai tahun ketiga operasional PPI Lugu dilaksanakan dengan struktur kelembagaan pelabuhan perikanan yang berlaku.
\end{abstract}

Kata Kunci: pangkalan pendaratan Ikan, nelayan, jaringan sosial, transaksi sosial, Simeulue

\begin{abstract}
The economic development of frontier islands through the Integrated Marine and Fisheries Development Program (SKPT) is intensively being carried out. This program is the main activity of Simeulue Regency by renovation of the cold storage, ice factory, air blast freezer, ship dock as well as building market and offices in the Lugu Fishing Port. The development of infrastructures is expected to encourage the growth of fisheries business, function (revitalization) of the Lugu Fishing Port, and increase the contribution of fisheries business field in the gross regional domestic product of Simeulue. The aim of this report is to understand social network and to find the strategy of the Lugu Fishing Port revitalization, field observation for the Lugu Fishing Port revitalization was conducted by a quick survey in January 2015 and deep interview about socio economic aspect and fisheries business was conducted on 30 fishers and 3 fish traders (toke bangku) in April 2016. Data was analyzed descriptive based on economic theory of Handerson and Quant and the sociology-economy theory of Damsar and Indrayani. Results of this study showed that role and capacity of business, social network, and social exchange in
\end{abstract}


fisheries business in Simeulue not used as a references in arranging the policy of the Lugu Fishing Port revitalization. As a result, the fishing port has not functioned until August 2016. This study recommends the operational of the Lugu Fishing Port to be conducted in two steps: short-term in giving concession to companies/businessman having the fund and wide market network to manage cold storage or ice factory, and long term starting from the third year by operating the fishing port based on the fishing port organizational structure applied.

Keywords: fishing port, fisher's, social networking, social transaction, Simeulue

\section{PENDAHULUAN}

Pangkalan Pendaratan Ikan (PPI) Lugu, merupakan satu dari 51 tempat pendaratan ikan di Kabupaten Simeulue. PPI ini, pertama kali dibangun dengan dana hibah Islamic Development Bank (IDB) tahun 2007-2008 untuk memfasilitasi aktivitas nelayan di Simeulue, dan dipersiapkan untuk menggantikan lokasi pendaratan ikan di Pajak Inpres di Kota Sinabang.

Pada rancangan pembangunan ekonomi Simeulue 2014 - 2019, PPI Lugu menjadi pusat perdagangan dan distribusi ikan untuk kawasan Simeulue dan kawasan Aceh Daratan, namun, maksud tersebut belum terwujud sampai survei dilakukan pada Januari 2015. Secara teknis hal itu disebabkan, oleh: (a) Fasilitas pengisian Bahan Bakar Minyak, SolarPacked DealerNelayan (SPDN) belum tersedia; (b) Fasilitas yang dibangun dengan dana hibah IDB (Cold Storage, Air Blast Freezer) telah rusak karena tidak pernah digunakan; (c) Kelembagaan formal pengelola aset PPI Lugu belum ada, walaupun PPI merupakan aset Pemerintah Daerah Simeulue; (d) Pada kawasan PPI Lugu belum tersedia sarana pertokoan, pergudangan, perkantoran, ruang serbaguna dan ruang pertemuan, dan; (e) Infrastruktur jalan, instalasi listrik dan air bersih pada PPI Lugu tidak terawat, sehingga perlu perbaikan.

Kondisi diatas, mendorong program SKPT Simeulue di PPI Lugu, merenovasi cold storage, air blast freezer, pabrik es dan tempat pelelangan ikan sejak September sampai Desember 2015. Program ini juga membangun kantor terpadu, kios-kios pedagang dan pengolahan ikan, bahkan tahun 2016 akan disiapkan SPDN (Solar Packed Dealer Nelayan) agar armada perikanan Simeulue mau beraktivitas di pangkalan pendaratan ikan tersebut.

Total investasi pemerintah pusat untuk merenovasi dan membangun berbagai fasilitas di PPI Lugu selama tahun 2015 sekitar Rp 15 Milyar, namun PPI tersebut belum bisa beroperasi. Pada awal tahun 2016 di PPI Lugu pemerintah telah menempatkan dua petugas Pelabuhan Perikanan Samudera Bungus untuk mengelola PPI tersebut.

Pembangunan fisik yang dilakukan selama tahun 2015 di PPI Lugu ternyata tidak dilengkapi dengan informasi aspek sosial ekonomi, sehingga merupakan salah satu faktor yang menyebabkan revitalisasi PPI Lugu tidak terwujud sampai akhir Agustus 2016. Armada perikanan di Simeulue tetap beraktivitas di tempat pendaratan ikan Pajak Inpres Kota Sinabang yang jaraknya $\pm 2 \mathrm{Km}$ dari PPI Lugu. Kondisi ini terjadi, karena para pelaku usaha perikanan secara swadaya telah mengembangkan jaringan sosial yang kuat dalam jual beli ikan di luar PPI Lugu, sebagai respon dari pasifnya partisipasi pemerintah daerah mengatasi permasalahan perdagangan ikan.

Tulisan ini mencoba mempelajari aspek sosial ekonomi nelayan perikanan rakyat di Simeulue, agar fasilitas yang dibangun tersebut dapat dimanfaatkan, dan revitalisasi PPI Lugu dapat diwujudkan. Lebih lanjut, penelitian ditujukan untuk mempelajari jaringan sosial pada bisnis perikanan tangkap di Simeulue dan merumuskan strategi revitalisasi PPI Lugu agar pelabuhan perikanan tersebut dapat berfungsi.

\section{METODOLOGI}

Tulisan ini disusun berdasarkan hasil pengumpulan data dan informasi selama tiga periode di Simeulue. Periode pengumpulan data adalah sebagai berikut:

Periode pertama, akhir Januari 2015 melalui survei cepat, untuk mengumpulkan informasi umum tentang produksi perikanan, jumlah dan jenis armada perikanan, pasar, daya serap pasar dan tujuan pemasaran serta sebaran tempat pendaratan ikan termasuk kondisi infrastruktur pangkalan/ tempat pendaratan ikan.

Periode kedua, April 2016 dilakukan pengumpulan data terhadap: (a). 30 nelayan 
pemilik armada 5-20 GT yang dipilih acak, masingmasing 10 responden dari 21 nelayan pemilik di Kecamatan Simeulue Timur, 10 responden dari 16 nelayan pemilik di Kecamatan Teupah Selatan, dan 10 responden dari 13 nelayan pemilik di Kecamatan Teupah Tengah. Ketiga kecamatan tersebut lokasinya berdekatan dengan PPI Lugu. (b). Tiga "toke bangku" yang dipilih dari 10 "toke bangku" yang terdapat di Simeulue. Pengumpulan data tersebut dilakukan dengan daftar pertanyaan terstruktur yang dilakukan oleh Penyuluh Perikanan Tenaga Bantu. Data yang dikumpulkan pada tahap kedua, mencakup karakteristik responden, hasil tangkapan per trip, penguasaan aset, struktur ongkos dan pendapatan, trip penangkapan ikan, jumlah tenaga kerja yang ikut dalam bisnis penangkapan ikan, jumlah ikan yang diperdagangkan per hari, modal dan sumber modal.

Pada periode kedua dilakukan juga, diskusi kelompok dengan 10 anggota Gabungan Penggalas Ikan Pajak Inpres (Gapipres) Sinabang, untuk mendapat informasi tentang jumlah penggalas dan kemampuan penggalas (pedagang pengecer) dalam perdagangan ikan hasil tangkapan nelayan.

Periode ketiga dilakukan sampai akhir September 2016, melalui komunikasi telepon dengan seorang informan kunci. Informasi yang dikumpulkan terkait dengan kegiatan bongkar muat di PPI Lugu, perkembangan operasional cold storage, pabrik es dan Air Blast Freezer serta perkembangan armada yang membongkar ikan di PPI Lugu.

Data sekunder untuk mendukung penelitian ini berasal dari Dinas Kelautan dan Perikanan Kabupaten Simeulue yang meliputi, total produksi perikanan, jumlah penggalas per kecamatan, jumlah armada perikanan di Simeulue menurut ukuran.

Data yang dikumpulkan pada tahap pertama dan kedua serta data sekunder diolah dengan statistik sederhana, dan hasilnya digunakan untuk menjelaskan berbagai fenomena sosial ekonomi terkait dengan PPI Lugu. Hasil analisa tersebut yang dilengkapi dengan informasi dari informan kunci dielaborasi untuk menjelaskan perilaku yang terjadi di sekitar PPI Lugu mengikuti teori ekonomi (Henderson and Quant, 1980) dan sosiologi ekonomi (Damsar dan Indrayani, 2013).

\section{HASIL DAN PEMBAHASAN}

\section{Jaringan Sosial Toke Bangku pada Bisnis Perikanan di Simeulue}

Data Dinas Kelautan dan Perikanan Kabupaten Simeulue menunjukkan produksi ikan hasil tangkapan nelayan Simeulue 2015 adalah 10.691 ton. Komposisi ikan hasil tangkapan yang diperdagangkan itu terdiri dari: ikan karang $(23,1 \%)$, Pelagis Besar $(52,9 \%)$ serta ikan Pelagis Kecil $(24,0 \%)$. Di Simeulue, aktivitas pendaratan dan perdagangan ikan tersebut, $65 \%$ terjadi pada tempat pendaratan ikan Pajak Inpres Kota Sinabang. Sisanya tersebar pada 50 lokasi pendaratan ikan dengan jumlah yang berbeda antara satu lokasi dengan lokasi lainnya.

"Toke bangku" (pedagang ikan yang memiliki modal dan menguasai sebagian besar perdagangan ikan) jumlahnya di Kabupaten Simeulue sekitar 10 orang, umumnya beroperasi pada tempat pembongkaran ikan dengan armada $>10$ GT (terutama pada tempat pendaratan ikan di Pasar Inpres Kota Sinabang). Setiap "Toke Bangku", mempunyai jaringan sosial tersendiri dengan beberapa nelayan yang mendaratkan ikan di Kawasan Pasar Inpres tersebut dan pedagang ikan di Daratan Aceh dan Medan.

Pada pusat pendaratan ikan di Pasar Inpres Sinabang, kekuasaan dan dominasi "Toke Bangku" dalam pertukaran sosial pada perdagangan ikan sangat kuat. Kekuatannya sepertiyang digambarkan Ritzer (2014) dan Zeitlin (1995) meliputi kemampuan menetapkan lokasi membongkar ikan, siapa yang membongkar ikan dan kepada siapa ikan harus didistribusikan.

Peran "toke bangku" cukup besar. "Toke bangku" membiayai investasi armada penangkapan ikan dan operasional penangkapan ikan kepada beberapa pemilik kapal penangkapan ikan. Di Simeulue Timur $25 \%$ responden menerima modal investasi armada tangkap dari "toke bangku", sisanya memanfaatkan dana sendiri untuk investasi. Biaya investasi armada tangkap di Simeulue Timur sekitar Rp. 27,34 Juta per unit. Pada Kecamatan Teupah Selatan 50\% responden memanfaatkan investasi untuk armada tangkap dari "toke bangku" dan sisanya dari bantuan pemerintah. Investasi armada penangkapan ikan di Teupah Selatan sekitar Rp. 25,242 juta per unit. Sedangkan di Teupah Tengah seluruh responden menggunakan 
dana pribadi untuk investasi armada penangkapan ikan, biaya investasi tersebut sekitar Rp. 5 juta per unit armada.

Di Simeulue, "toke bangku" juga memberi biaya operasional penangkapan ikan kepada nelayan. Nelayan yang menerima biaya operasional tersebut harus menjual ikan hasil tangkapan kepada "toke bangku" tersebut. Penjualan ikan dalam volume besar sulit dilakukan di Simeulue, karena jumlah pedagang besarnya yang terbatas.

Di Simeulue Timur rata-rata biaya operasional penangkapan ikan yang diterima nelayan dari "toke bangku" adalah Rp. 4,6 juta per trip, sedangkan di Teupah Selatan sekitar Rp. 3,4 juta per trip dan di Teupah Tengah rata-rata sebesar Rp. 4 juta per trip.

Investasi dan biaya operasional dari "toke bangku" kepada nelayan pada bisnis perikanan di Pajak Inpres Kota Sinabang menunjukkan pemilik modal telah mengikat nelayan. Ikatan ini merupakan jaringan sosial (relasi) yang dibangun "toke bangku" untuk mendapatkan ikan karang, beberapa jenis ikan pelagis besar dan ikan pelagis kecil. Jaringan sosial ini sangat kuat. Pemilik modal harus mengendalikan investasi yang lain di Pajak Inpres tersebut, sehingga sulit bagi mereka ikut berpartisipasi merevitalisasi PPI Lugu.

Jaringan sosial antara "toke bangku" dengan nelayan tersebut menurut ilustrasi Damsar (1997), merupakan tindakan untuk menjaga kepercayaan bisnis perikanan antara "toke bangku" dengan pedagang besar di Medan, Meulaboh dan Labuhan Haji. Jaringan sosial tersebut adalah ikatan sosial yang aktif dan resiprokal (saling membutuhkan) untuk mendapatkan ikan dan memasarkan ikan hasil tangkapan nelayan. Pada jaringan sosial tersebut, terjadi pertukaran sosial, menurut Blau (1964) dalam Amal (2014) dan Baldwin (1978) digerakkan oleh dorongan kekuasaan, dominasi dan kepentingan "toke bangku" untuk mengembangkan usahanya.

Kekuasaan "toke bangku" pada jaringan sosial dengan nelayan dapat dilihat dalam bentuk perbedaan harga transaksi (Williamson, 1995) ikan karang dan pelagis besar. Ikan karang (> $3 \mathrm{Kg}$ ) dan tuna sirip kuning ( $>25 \mathrm{Kg}$ ) serta cakalang ( $>5 \mathrm{Kg}$ ) dengan kualitas super harganya lebih tinggi dari ikan yang sama dengan ukuran yang lebih kecil dengan kualitas baik. Dominasi "toke bangku" terlihat dari kemampuan berinvestasi dan kemampuan "toke bangku" membeli dan memobilisasi ikan dari Simeulue ke luar Simeulue dalam jumlah besar. Kepentingan "toke bangku" dapat dicermati dari strategi mendapatkan jenis ikan karang dan pelagis besar dari nelayan pada berbagai lokasi untuk pasokan ikan ke pasar tujuan.

Pertukaran sosial pada jaringan sosial yang dibangun "toke bangku" tersebut dipandang nelayan telah menyelamatkan kehidupan mereka, karena secara tidak langsung ikut membantu perekonomian di desa mereka. Oleh sebab itu, jaringan sosial yang dikembangkan setiap "toke bangku" melalui uang yang dibelanjakannya merupakan bentuk "community safety net" bagi masyarakat desa. Gambaran ini, berbeda dengan "social safety net", dimana peran pemerintah sangat dominan untuk mengatasi kesulitan perekonomian masyarakat nelayan (Honorati et al., 2015 dan Thomas et al., 2011).

Community safety net yang dibangun "toke bangku" terbentuk melalui kepercayaan dalam periode relasi sosial yang panjang (Williamson, 1981), sehingga jaringan sosial tersebut terus berfungsi dan resiprokal.

Relasi bisnis perikanan seperti ini di Pajak Inpres Kota Sinabang membentuk komunitas dalam kekuasaan "toke bangku". Komunitas ini secara sosial membutuhkan "toke bangku" dan secara ekonomi "toke bangku" memerlukan nelayan untuk mendapatkan ikan. Relasi ini akan tetap bertahan di tempat pendaratan ikan Pajak Inpres Kota Sinabang dan sulit dipindahkan ke PPI Lugu. Perlu dicatat, dalam perdagangan ikan antara jaringan sosial "toke bangku" dengan pedagang di daratan Aceh dan Medan transaksi penjualan dilakukan dengan sistem konsinyasi 3 sampai 5 hari setelah ikan diterima. Sehingga setiap "Toke Bangku" harus memiliki modal operasional per hari minimal $\mathrm{Rp}$. 30 Juta.

Ciri jaringan sosial yang dibangun "toke bangku" terletak pada kekuatan mengikat sumber suplai ikan (nelayan), kekuatan persediaan modal, dan akses pasar di luar Simeulue.

\section{Jaringan Sosial "Penggalas" dalam Perdagangan Ikan}

Pada tempat pendaratan ikan dimana "toke bangku" tidak berperan, kehadiran pedagang pengumpul desa sangat penting. Pedagang ikan pengumpul ini disebut penggalas oleh masyarakat Simeulue. Penggalas membangun jaringan sosial dengan nelayan perahu motor tempel (dikenal armada robin). Relasi ini bertujuan mendapatkan 
ikan untuk dijual eceran ke berbagai desa di Simeulue dengan menggunakan kendaraan roda dua.

Pengamatan lapangan pada April 2016, menunjukkan penggalas ikan yang telah punya jaringan sosial pada berbagai desa, mencoba membangun jaringan sosial dengan "toke bangku" di Pasar Inpres Kota Sinabang. Jaringan sosial ini tidak kuat, karena kekuasaan dan dominasi penggalas lebih lemah dibandingkan dengan "toke bangku". "Toke bangku" menilai kemampuan transaksi 'penggalas ikan' ini sangat terbatas. Penggalas hanya membeli ikan karang dan pelagis kecil untuk konsumsi rumah tangga dengan volume yang terbatas. Modal penggalas per hari antara Rp. 500 ribu sampai $R p .750$ ribu. Jika modal penggalas untuk membeli ikan tidak mencukupi maka mereka akan mengambil ikan tersebut dan dalam satu atau dua hari kemudian harga ikan akan dibayar.

Pada pertengahan tahun 2016, mulai muncul penggalas ikan menetap yang menawarkan ikan di pinggir jalan pada lokasi strategis di Kota Sinabang. Penggalas tersebut menjadi pesaing dari penggalas yang telah lama berjualan ikan pada pasar ikan di Pajak Inpres Kota Sinabang. Penggalas pada pasar tersebut mengklaim mereka adalah penggalas resmi di Simeulue, karena telah tergabung dalam organisasi "Gabungan Penggalas Ikan Pajak Inpres Simeulue" (Gapipres) dan Koperasi Gapipres Mandiri Simeulue. Organisasi ini, menghimpun 30 pedagang ikan yang berjualan pada Pasar Inpres Kota Sinabang. Perwakilan Gapipres pada forum resmi selalu meminta pemerintah untuk menertibkan penggalas ikan yang berjualan ikan di pinggir jalan pada berbagai sudut kota Sinabang. Menurut mereka kehadiran penggalas / penjual ikan di pinggir jalan tersebut semakin menurunkan omzet penjualan ikan di Pasar Inpres Kota Sinabang. Persaingan dalam perdagangan ikan ini menunjukkan daya serap ikan di Simeulue sangat terbatas. Ikan hanya diserap untuk konsumsi rumah tangga, karena belum terdapat industri pengolahan hasil perikanan yang dapat menyerap ikan secara regular dalam jumlah yang besar.

Organisasi yang dibentuk penggalas ikan di Pasar Inpres Kota Sinabang menurut Soekanto (2003) merupakan kelembagaan asosiasi dengan norma bisnis lokal (hanya berlaku di Pasar Inpres Sinabang). Asosiasi ini bukan merupakan organisasi untuk mendorong peningkatan daya serap ikan pada pasar lokal di Simeulue, tetapi sebagai organisasi untuk memperkuat daya tawar kepada pemerintah untuk mendapatkan berbagai keuntungan agar bisnis mereka dapat berjalan baik.

Tabel 1 menunjukkan, jumlah ikan yang didaratkan per hari rata-rata mencapai 189,9 Ton (5.698,1 Ton per Bulan) dan jumlah tersebut tersebar pada berbagai lokasi. Omzet penjualan penggalas per hari per orang rata-rata $150 \mathrm{~kg}$ ikan. Total ikan yang diperdagangkan oleh 270 penggalas ikan di

Tabel 1. Jumlah Armada Perikanan, Produksi dan Perdagangan Ikan di Simeulue, 2016. Table 1. Number of Fishing Vessel, Production, and Fish Trades in Simeulue, 2016.

\begin{tabular}{|c|c|c|c|c|}
\hline $\begin{array}{c}\text { Lokasi (Kecamatan)/ } \\
\text { Location (District) }\end{array}$ & $\begin{array}{c}\text { Jumlah Armada } \\
\text { Perikanan (Unit) }{ }^{a} / \\
\text { Amount of } \\
\text { Fishing Vessels } \\
\text { (Unit) }^{\text {a }}\end{array}$ & $\begin{array}{l}\text { Produksi Ikan } \\
\text { Per Bulan } \\
\text { (Ton)/Fish } \\
\text { Production } \\
\text { per Month } \\
\text { (Tons) }\end{array}$ & $\begin{array}{c}\text { Potensi Perdagangan } \\
\text { Penggalas Ikan Per } \\
\text { Bulan (Ton)/Trading } \\
\text { Potency of Fish } \\
\text { Retailer per Month } \\
\text { (Tons) }\end{array}$ & $\begin{array}{c}\text { Neraca Potensi } \\
\text { Perdagangan Ikan } \\
\text { Simeulue per Bulan } \\
\text { (Ton)/Balance of } \\
\text { Trade Fish Trading } \\
\text { Potency in Simeulue } \\
\text { per Month (Tons) }\end{array}$ \\
\hline Simeulue Timur & 723 & 989.4 & 225.0 & 764.4 \\
\hline Teluk Dalam & 340 & 538.3 & 94.0 & 444.3 \\
\hline Simeulue Barat & 441 & 698.2 & 116.0 & 582.2 \\
\hline Alafan & 250 & 395.8 & 95.0 & 300.8 \\
\hline Salang & 293 & 463.9 & 111.5 & 352.4 \\
\hline Simeulue Tengah & 345 & 546.2 & 72.0 & 474.2 \\
\hline Teupah Barat & 251 & 397.4 & 54.0 & 343.4 \\
\hline Teupah Selatan & 339 & 1.019 .7 & 54.0 & 965.7 \\
\hline Teupah Tengah & 231 & 288.3 & 108.0 & 180.3 \\
\hline Simeulue Cut & 228 & 361.0 & 108.0 & 253.0 \\
\hline Jumlah/Total & 3,441 & $5,698.1$ & $1,037.5$ & $4,660.6$ \\
\hline
\end{tabular}

Keterangan : a Dinas Kelautan dan Perikanan Kab. Simeulue (2016) /Remark: Simeulue Marine dan Fisheries Office (2016)/

Sumber:diolah dari hasil Survei (April 2016)/Source: obtained from primary data (April 2016) 
seluruh Simeulue sekitar 34,6 Ton per hari $(1.037,5$ Ton per bulan). Jumlah tersebut telah termasuk yang diperdagangkan oleh penggalas pada pasar ikan di Pajak Inpres Kota Sinabang (2,18 Ton per hari). Dengan demikian setiap hari di Simeulue terdapat potensi ikan yang dapat diperdagangkan oleh "toke bangku" sekitar 155,4 Ton ikan (4.660,6 Ton ikan per bulan). Hasil survei menunjukkan kemampuan 10 "toke bangku" memperdagangkan ikan dari Simeulue adalah 98,92 Ton per hari, sehingga setiap hari di Simeulue terdapat surplus ikan sekitar 56,5 Ton yang tersebar pada berbagai lokasi pendaratan ikan.

Surplus ikan tersebut biasanya bulan Februari, Maret dan April serta ketika musim barat (karena transportasi laut tidak ada), sehingga selalu mendistorsi harga ikan di Simeulue, dan menyebabkan sebagian ikan hasil tangkapan "di kubur" di tepi pantai.

Data pada Tabel 1 menunjukkan dari total ikan yang didaratkan di Simeulue per bulan, jaringan sosial penggalas hanya mampu memperdagangkan ikan sekitar 18,2\% ikan, sementara jaringan sosial "toke bangku" hanya sekitar 52,08\%. Hal ini menunjukkan kapasitas jaringan sosial penggalas dan "toke bangku" dalam perdagangan ikan di Simeulue masih terbatas, karena kendala penyimpanan, distribusi, modal dan akses pasar.

Jaringan sosial penggalas ikan tersebut memiliki kekuatan modal yang terbatas, jangkauan pemasaran pada beberapa desa di Simeulue, konflik horizontal terjadi antara penggalas Pajak Inpres dengan penggalas yang menjual ikan pada berbagai sudut jalan di Kota Sinabang.

\section{Upaya Revitalisasi PPI Lugu}

Revitalisasi PPI Lugu di Simeulue, tidak dapat hanya mengandalkan renovasi dan membangun fasilitas yang diperlukan oleh aktivitas perikanan, distribusi dan perdagangan ikan. Buktinya infrastruktur yang telah dibangun pada tahun 2015, tersebut belum berfungsi sampai Agustus 2016. Revitalisasi tersebut memerlukan informasi tambahan tentang kekuatan dan kapasitas jaringan sosial yang berperan dalam perdagangan ikan di Simeulue, karena jaringan sosial (terutama yang dibangun "toke bangku") sangat kuat dan sangat sulit operasionalnya dipindahkan ke PPI Lugu. Upaya membuat kesepakatan melalui pertemuan resmi yang dipimpin oleh pejabat daerah untuk revitalisasi PPI Lugu pada akhir 2015 dan awal 2016, memindahkan aktivitas perikanan dari tempat pendaratan ikan Pajak Inpres Kota Sinabang ke PPI Lugu sulit dilaksanakan. Hal ini disebabkan karena "toke bangku" telah berinvestasi cukup besar dalam berbagai bisnis - (seperti: bengkel perbaikan mesin kapal, warung kopi, penjualan BBM, maupun perbekalan melaut) - yang menunjang aktivitas perikanan di tempat pelelangan ikan Pajak Inpres Kota Sinabang. Dengan kata lain jaringan sosial yang telah terbentuk cukup lama tidak mungkin dilarang walaupun kurang mendukung revitalisasi PPI Lugu.

Tulisan ini melihat revitalisasi PPI Lugu tersebut dapat dilakukan dengan memberi akses kepada pengusaha (investor) dengan plat form bisnis "sosial enterpreneur"1 (Mair and Marti, 2005) untuk memanfaatkan dan mengelola cold storage, ABF dan pabrik es yang terdapat di PPI Lugu. Akses ini harus diberikan oleh Pemerintah Kabupaten Simeulue, karena di Simeulue terdapat sekitar 56,5 Ton ikan per hari (1.693 ton ikan per bulan) yang potensial diperdagangkan ke luar Simeulue dan tersebar pada berbagai tempat pendaratan ikan.

Pengusaha (investor) dengan plat form bisnis kapitalis ${ }^{2}$ akan berkonflik dengan jaringan sosial yang mapan di tempat pendaratan ikan Pajak Inpres Kota Sinabang, walaupun mendapat akses memanfaatkan berbagai fasilitas di PPI Lugu. Pengusaha tipe ini telah keluar dari bisnis ikan di pasar Simeulue sejak April 2016, karena mengandalkan pasokan ikan dari nelayan di tempat pendaratan ikan Pajak Inpres Kota Sinabang, sehingga berkonflik dengan "toke bangku" yang terdapat di Pajak Inpres Kota Sinabang.

Upaya untuk mencari pengusaha dengan plat form bisnis "sosial entrepreneur telah dilakukan melalui seleksi dalam temu bisnis yang dilakukan di Jakarta dan di Simeulue. Dengan situasi PPI Lugu yang demikian pengusaha (investor) PT. Prima Pangan Madani ikut dalam program revitalisasi PPI Lugu dengan berbagai persyaratan administrasi.

\footnotetext{
${ }_{1}^{1}$ Pengusaha sosial enterpreneur adalah pengusaha yang menjalankan bisnis dengan membentuk kluster usaha dalam masyarakat (jaringan sosial baru yang tidak menimbulkan konflik dengan jaringan sosial yang ada) sehingga masyarakat dalam kluster usaha itu ikut berperan untuk memasok produk yang dipasarkan oleh entrepreneur tersebut.

${ }^{2}$ Pengusaha yang hanya berbisnis untuk mendapat keuntungan dan membesarkan usahanya sendiri.
} 
Investor ini menilai punya potensi besar dalam perdagangan ikan (terutama ikan karang) untuk memasok kebutuhan ikan di Dubai (5 ton per bulan) dan pasar ikan di Jakarta dan Medan melalui jaringan pasar yang telah dikembangkannya sejak lama.

Sesuai dengan plat form bisnis sosial entrepreneur PT. Prima Pangan Madani yang mendapat akses mengelola cold storage, dan air blast freezer sejak September 2016, telah merintis pembelian ikan dengan membangun kluster-kluster bisnis (jaringan sosial) baru pada beberapa tempat pendaratan ikan di Simeulue, tanpa mengganggu jaringan sosial yang telah dibangun oleh 10 'toke bangku" yang terdapat di Simeulue. Bisnis ini secara perlahan telah berjalan dan ikan yang dibeli termasuk ikan perairan umum daratan terutama ikan gabus (Ophiocephalus striatus).

Operasionalisasi seluruh fasilitas PPI Lugu memerlukan proses panjang, namun kehadiran investor PT Prima Pangan Madani dengan akses beberapa fasilitas di PPI Lugu, telah mendorong beberapa armada perikanan mulai membongkar ikan di PPI Lugu setiap hari. Ikan yang dibongkar di PPI ini telah ada pembeli termasuk dari PT Prima Pangan Madani.

Revitalisasi PPI Lugu memerlukan berbagai pembenahan, termasuk kelembagaan pengelola aset di PPI, kelembagaan syahbandar yang mengatur keluar masuk kapal penangkap ikan dan regulasi manajemen mengelola kawasan PPI Lugu. Regulasi tersebut diperlukan agar PPI Lugu menjadi lokasi menarik dalam bisnis ikan di Simeulue.

\section{KESIMPULAN DAN IMPLIKASI KEBIJAKAN}

Jaringan sosial merupakan faktor penting untuk membangun bisnis perikanan di pulau terdepan. Pada kasus di Simeulue, jaringan sosial yang dibangun oleh "toke bangku" dan penggalas tidak mampu memasarkan kelebihan suplai ikan sekitar 56,5 Ton per hari yang dihasilkan oleh armada penangkapan ikan di Simeulue. Kemampuan jaringan sosial penggalas dan "toke bangku" dalam perdagangan ikan masih sangat lemah. Jaringan sosial tersebut juga tidak handal mempertahankan pangsa pasar di pasar tujuan melalui persaingan harga ikan yang kompetitif.

Oleh sebab itu untuk memperbesar kapasitas jaringan sosial diluar PPI Lugu, maka harus dilakukan : a. Peningkatan kapasitas manajerial pengelola bisnis perikanan di Simeulue melalui asistensi pelaku usaha dalam jaringan sosial penggalas, dan "toke bangku", sehingga dengan modal dan dominasi yang dimiliki dapat meningkatkan akses pasar.

b. Memperbesar daya serap pasar lokal Simeulue dengan mendorong "toke bangku" ikut dalam bisnis berbagai produk inovatif hasil perikanan dan produk turunan berbahan baku ikan dalam masyarakat Simeulue.

c. Satuan kerja pemerintah daerah yang terkait dengan Sektor Perikanan selain Dinas Perikanan dan Kelautan, seperti: Dinas Perindustrian, Dinas Koperasi \& UMKM serta Dinas Pariwisata harus aktif mempromosikan produk turunan berbahan baku ikan pada berbagai event.

Sedangkan untuk memfungsikan PPI Lugu yang memiliki berbagai fasilitas, disusun beberapa strategi, yaitu:

1. Dalam jangka pendek:

a. Harus mendorong pengusaha yang memiliki plat form bisnis "sosial entrepreneur (PT. Prima Pangan Madani) berpartisipasi mandiri dalam mengembangkan bisnis perikanan di Simeulue.

b. Pemerintah Daerah Kabupaten Simeulue harus membuat Memorandum of Understanding (MoU) dengan pengusaha tersebut agar investasinya aman dan terjamin. MoU itu akan menjamin penyerapan ikan Simeulue karena pengusaha telah memiliki jaringan pasar yang kuat dan pasti serta modal yang cukup untuk beroperasi di Simeulue. MoU tersebut memberi insentif pada pengusaha untuk mendapat izin pemanfaatan berbagai fasilitas yang terdapat di PPI Lugu selama 3 tahun.

c. Pada tahun 3, mewajibkan pengusaha tersebut berinvestasi di kawasan PPI Lugu dengan membangun fish processing plant sebagai basis operasi perusahaan dalam membeli dan mengemas hasil olahan perikanan di Simeulue.

d. Pada tahun ke 3, mewajibkan perusahaan tersebut membangun jaringan sosial baru dan mengintegrasikan jaringan sosial yang dibangun oleh beberapa "toke bangku" melalui MoU dan mewajibkan "toke bangku" memasok ikan ke PPI Lugu dalam jumlah yang disepakati dengan harga pasar. 
2. Dalam jangka panjang:

a. Mulai tahun ke 2 sampai tahun ke 5, mewajibkan perusahaan tersebut membentuk kluster industri pengolahan hasil perikanan secara bertahap di Simeulue, untuk membangun industri pengolahan berbasis rumah tangga dengan standar proses pengolahan ditetapkan perusahaan. Agar produk tersebut dapat dikemas oleh perusahaan untuk dipasarkan ke berbagai daerah. Langkah ini akan meningkatkan permintaan ikan segar di Simeulue.

b. Pada tahun ke 3 pemerintah daerah Kabupaten Simeulue, mulai menguji coba kelembagaan pengelolaan PPI Lugu sesuai dengan peraturan pemerintah, untuk mengatur berbagai kegiatan yang telah berjalan di PPI Lugu yang dilakukan oleh pengusaha.

Dengan jaringan sosial yang direkomendasikan tersebut, maka kegiatan tersebut tidak merusak jaringan sosial yang telah ada. Jaringan sosial yang baru akan bermitra dengan jaringan sosial yang ada sehingga mampu memperbesar daya serap pasar perikanan di Simeulue dan memperluas jangkauan pasar produk Simeulue lebih dari 155,4 Ton ikan per hari.

\section{UCAPAN TERIMA KASIH}

Penulis mengucapkan terima kasih kepada Kepala Pusat Penelitian Sosial Ekonomi Kelautan dan Perikanan, yang telah memberi kepercayaan kepada penulis menjadi penanggungjawab pelaksanaan kegiatan pembangunan Technopark di Simeulue dari tahun 2015 sampai tahun 2016. Terima kasih juga kepada Penyuluh Perikanan Tenaga Bantu yang bersedia membangun kerjasama dengan penulis dan tim Kementerian Kelautan dan Perikanan, sehingga tanpa pamrih bersedia mengumpulkan berbagai data yang dapat digunakan untuk tujuan pembangunan perikanan di Simeulue.

\section{DAFTAR PUSTAKA}

Baldwin, D.A. 1978. Power and social Exchange. Dartmouth College. http://www/princeton.edu_/ dbaldwin/selected $\% 20$ articles/Baldwin $\% 20$ (1978)\%20Power\%20and\%20Social\%20 Exchange.pdf. Diakses pada tanggal: 17 Agustus 2016.

Amal, M. K. 2014. State of The Art Teori Pertukaran Sosial: dari Teori Pertukaran Sosial Klasik sampai Teori Pertukaran Kontemporer. http://beasiswa. unair.ac.id/sites/default/files/perpanjangan/2013/ ki_M\%20Khusna\%20Amal_5064.pdf. Diakses pada tanggal 17 Agustus 2016.

Damsar dan Indrayani. 2013. Pengantar Sosiologi Ekonomi. Edisi ke 3. Kencana Prenada Media Group. Jakarta.

Damsar. 1997. Sosiologi Ekonomi. Penerbit Rajawali. Jakarta.

Henderson, J. M. and R. E. Quant. 1980. Micro Economic Theory: A Mathematical Approach,

Honorati, M. U., Gentilini and R. Yemstov. 2015. The State of Social Safety Nets, 2015. The World Bank Group.

Mair, J. and I. Marti. 2005. Social Enterpreneurship Research: A Source of Explanation, Prediction, And Delight. ISEI Working Paper. No.564. Univ. of Navarra. Spain.

Ritzer, G. 2014. Teori Sosiologi Modern. KencanaPrenada Media. Jakarta.

Soekanto, S. 2003. Sosiologi: Suatu Pengantar. Radja Grafindo Persada. Jakarta.

Thomas. V., C. Grey, M. Huppi and J. Litvack. 2011. Social Safety Net. An Evaluation of World Bank Support. 2000 - 2010. Independent Evaluation Group - World Bank

Williamson, O. E. 1995. Hirarchies, Markets, and Power in The Economy: An Economic Perspectives. Journal of Indisutrial and Corporate Changes. Oxford University Press.

Williamson, O. E. 1981. The Economics of Organisation: The Transaction Cost Approach. American Journal of Sociology. Vol. 87(3). Page:548 - 577.

Zeitlin, I. M. 1995. Memahami Kembali Sosiologi. UGM Press. 